\title{
Role of pleural fluid analysis in establishing the diagnosis of pleural effusion Experience in College of Medical Sciences-Teaching Hospital, Bharatpur, Nepal
}

\author{
G. G. Swamy ${ }^{1}$, T. M. V. Prasada Rao², P. Sunitha ${ }^{3}$, S. Madhuravani ${ }^{4}$ \\ ${ }^{1}$ Associate Professor, Dept. of Pathology, ${ }^{2}$ Professor, Dept. of Community Medicine, ${ }^{3}$ Lecturer, Dept. of Physiology, College \\ of Medical Sciences, Bharatpur, Chitwan, Nepal, ${ }^{4}$ Social Worker, Dept. of Community Medicine, Konaseema Institute of \\ Medical Sciences, Amalapuram, Andhra Pradesh, India
}

\begin{abstract}
Aspiration of serous cavities is a simple and relatively non-invasive technique to achieve a diagnosis. The information provided by body fluid analysis serves several functions; it is a complete diagnostic modality which aims at pointing out the etiology of effusion as well as in certain cases, a means of prognostication of the disease process. The diagnostic performance of the cytological study of the fluid may be attributable to the fact that the cell population present in sediment. Thus, this study was aimed to assess the role of pleural fluid analysis in establishing the cause of pleural effusion. A retrospective study was carried out in the Department of Pathology, College of Medical Sciences Teaching Hospital, Bharatpur from July 2008 to July 2010. Two hundred samples of pleural fluid were examined for total cell count, cell type and cellular features along with biochemical study to find out the level of protein, glucose and chloride. In two hundred samples, $80 \%$ were exudative and $20 \%$ were transudative. Cirrhosis and congestive cardiac failure were commonest causative factors in transudatives. The cases of Tuberculosis were predominant in exudatives followed by malignancies. In the samples from all the tuberculosis patients, lymphocytes were the predominant cell type. Most of malignant effusions were exudatives. The primary site could be assessed by cytological examination in more than fifty percent of cases. The present study demonstrates that the most useful test in establishing the diagnosis of pleural effusion is pleural fluid analysis which includes mainly its cytology and cell count.
\end{abstract}

Key words: Pleural fluid, exudative, transudative.

Correspondence: G. G. Swamy

E mail: drgangadhar@ hotmail.com 
G.G. Swamy et al, Role of pleural fluid analysis in establishing........

\section{Introduction}

Abnormal accumulation of fluid in the pleural cavity is known as Pleural effusion. Diagnosis of Pleural effusion requires proper clinical evaluation and Cytological study.

Aspiration of pleural fluid is a simple and relatively non-invasive technique. Pleural fluid analysis and cytology remains the main stay for diagnosing the various diseases. ${ }^{1}$

Pleural fluid analysis can allow for follow up of the patient after treatment. ${ }^{2}$ Thoracocentesis can be safely performed to collect the pleural fluid. ${ }^{3}$ Both malignant and non-malignant cases of effusion can be identified by the relative technique of pleural fluid cytology. ${ }^{4}$ But some studies revealed pleural fluid cytology was not helpful in ascertaining few cases of pleural effusion of patients, there by indicating its limitation. ${ }^{4,5}$ Cytological study of the fluid may be attributable to the fact that the cell population present in sediment. ${ }^{6,7}$

In this background, we have done this study to confirm the importance of cytological examination of pleural fluid in the evaluation of neoplastic and non-neoplastic conditions of the pleural effusion.

\section{Materials and methods}

This study of pleural fluid cytology was hospital based retrospective study carried out in the Department of Pathology, College of Medical Sciences-Teaching hospital, Bharatpur from July 2008 to July 2010. Brief clinical history, physical examination, radiological investigations and routine hematological investigations such as Hemoglobin, Total Leucocyte count, RBC count,
Platelet count, ESR and coagulation profile as per our routine protocol were collected from files.

Almost in all cases, physicians used to perform the thoracentesis procedure for collection of pleural fluid and sent to the Pathology Department for evaluation. Consent was taken from all the patients before doing the procedure. Under aseptic measures, after $2 \mathrm{ml}$ of local anesthesia (2\% xylocaine), a 22 gauge needle attached to $10 \mathrm{ml}$ syringe introduced slowly into chest wall through the intercostal space, superior to seventh rib, periodically attempting to aspirate fluid. The entry to the pleural space was indicated by giving way. Two samples of $5 \mathrm{ml}$ of each of pleural fluid sent for analysis to cytology and biochemical analysis.

For cytological examination, the fluid was poured into the centrifuge tube and centrifuged for 10 minutes at 2000 RPM.The sediment was transferred to a clean glass slide and mixed with a part of $1 \%$ toluidine blue. After mounting with cover slip, the slide was observed under the microscope for immediate identification of cell morphology. Smears were prepared from the remaining sediment and stained with Geimsa, Hematoxylin and Eosin, Papanicolaous stains.

For hemorrhagic fluids, 0.1 N HCL was used as hemolysing agent (glacial acetic acid also used for it in few cases). After adding hemolysing agent, one drop of fluid was mixed with a drop of toluidine blue and the cells were counted in Neubauer Counting Chamber.

\section{Results}

In a total of 200 patients, 125 males and 75 females were included in this study. The ages of the patients 
ranged from ten years to seventy years, with maximum cases $(30 \%)$ in the sixth decade.

Of all the effusions, $30.5 \%$ were hemorrhagic, $28.5 \%$ turbid, $24 \%$ clear, $12.5 \%$ purulent, $2.5 \%$ were viscous and $2.0 \%$ opalalescent.

Transudates comprised 20\% of cases. Most of them were secondary to cirrhosis and congestive cardiac failure. (Table.1)

Overall $80 \%$ of pleural effusions were exudative in nature. Tuberculosis was the most common cause of exudative effusion (45\%). The second most common cause was malignancy $(30 \%)$, then paramalignancy (10\%), pneumonia (5\%), empyema $(5 \%)$ and other causes such as trauma, liver diseases; abscesses were altogether about $5 \%$. In more than half of the malignant effusions (54\%), predominant numbers of cells were lymphocytes. Polymorphonuclear cells were the predominant cell type in almost all samples of pneumonic effusions. (Table.2)

Most of the exudative effusions were hemorrhagic and most of the transudatives were clear in appearance.

Clinically, 48 cases were diagnosed to be tuberculous but with cytological and biochemical study only 42 cases were confirmed to be tuberculosis. All the samples of tuberculous effusion had lymphocyte count more than $50 \%$ (figure 1). About $80 \%$ cases had protein level more than 5 gms and $60 \%$ had glucose levels less than $60 \mathrm{mg} \%$ (Table 3). In the present study we found two cases of eosinophilic effusion with of $15 \%$ eosinophils.

Malignant cells were present in pleural fluid of 48 patients. Out of them about $80 \%$ were exudative and $20 \%$ were trasudative. $70 \%$ of malignant effusions were hemorrhagic.

Twenty eight cases of malignant pleural effusion were diagnosed as metastatic adenocarcinoma (figure 2). The cells were arranged as sheets, clusters and groups. About $60 \%$ patients were in the sixth decade. Diagnosis of Metastatic papillary carcinoma was made in eight cases. Smears showed clusters and papillary groups of large abnormal epithelial cells having large dense nuclei and conspicuous nucleoli along with coarse nuclear chromatin. $50 \%$ patients were in the sixth decade. All samples were exudative and hemorrhagic.

Mesothelioma was diagnosed in eleven samples. The cells were arranged mostly as single and dispersed fashion (figure 3 ). Some showed morule like configuration with knobby borders. All these samples were exudative and viscous in appearance. Metastatic small cell carcinoma was seen in the pleural fluid sample of 74 yrs old male patient who was clinically diagnosed as Tuberculosis. The fluid was hemorrhagic and exudative in nature. Smears showed scattered and loose cohesive clusters of small atypical epithelial cells appearing like lymphocytes, with large dense nuclei with coarse chromatin and scant cytoplasm. 
G.G. Swamy et al, Role of pleural fluid analysis in establishing........

Table 1: Clinical causes of transudative pleural effusion, total and differential cell count and biochemical features

\begin{tabular}{|c|c|c|c|c|c|c|c|c|c|c|}
\hline \multirow{2}{*}{$\begin{array}{l}\text { Causative } \\
\text { Factor }\end{array}$} & \multirow{2}{*}{$\begin{array}{c}\text { No. of } \\
\text { samples }\end{array}$} & \multicolumn{3}{|c|}{ TLC cells/cu.mm } & \multicolumn{5}{|c|}{ Predominant cells } & \multirow{2}{*}{$\begin{array}{c}\text { Protein }(\mathrm{gm} \%) \\
<3\end{array}$} \\
\hline & & $0-500$ & $500-1000$ & $>1000$ & Polymorphs & Lymphocytes & Eosinophils & Mesothelial & Malignant & \\
\hline Cirrhosis & 14 & 4 & 10 & - & 2 & 12 & - & - & - & 14 \\
\hline $\mathrm{CCF}$ & 13 & 11 & 2 & - & 2 & 11 & - & - & - & 13 \\
\hline RA & 1 & 0 & 1 & - & - & 1 & - & - & - & 1 \\
\hline Trauma & 1 & - & 1 & - & - & 1 & - & - & - & 1 \\
\hline \multicolumn{11}{|l|}{ Meig's } \\
\hline syndrome & 1 & 1 & - & - & - & 1 & - & - & - & 1 \\
\hline Malignancy & 10 & 1 & 1 & 8 & 2 & 8 & - & - & - & 10 \\
\hline
\end{tabular}

Table 2: Clinical causes of exudative pleural effusion, total and differential cell count and biochemical features

\begin{tabular}{|c|c|c|c|c|c|c|c|c|c|c|}
\hline \multirow{2}{*}{$\begin{array}{l}\text { Causative } \\
\text { Factor }\end{array}$} & \multirow{2}{*}{$\begin{array}{l}\text { No. of } \\
\text { samples }\end{array}$} & \multicolumn{3}{|c|}{ TLC cells/cu.mm } & \multicolumn{5}{|c|}{ Predominant cells } & \multirow{2}{*}{$\begin{array}{l}\text { Protein }(\mathrm{gm} \%) \\
\quad>3\end{array}$} \\
\hline & & $0-500$ & $500-1000$ & $>1000$ & Polymorphs & Lymphocytes & Eosinophils & Mesothelial & Malignant & \\
\hline Tuberculosis & 72 & 1 & 12 & 19 & 10 & 70 & - & - & - & 72 \\
\hline Pneumonia & 8 & - & 2 & 6 & 8 & - & - & - & - & 8 \\
\hline Empyema & 8 & - & 2 & 6 & 8 & - & - & - & - & 8 \\
\hline Trauma & 2 & - & - & 2 & 2 & - & $15 \%$ & - & - & 2 \\
\hline Others & 6 & - & 6 & - & 2 & 4 & - & - & - & 6 \\
\hline Paramalignar & ant 16 & - & 10 & 6 & 6 & 10 & - & - & - & 16 \\
\hline Malignant & 38 & 3 & 25 & 10 & 6 & 12 & - & 5 & 15 & 38 \\
\hline
\end{tabular}


Journal of College of Medical Sciences-Nepal,2010, Vol-6,No-4

Table 3: Tuberculous effusion lymphocyte count and biochemical values.

\begin{tabular}{ccccccr}
\hline No. of samples & \multicolumn{2}{c}{ Lymphocyte count (\%) } & \multicolumn{2}{c}{ Protein (gm\%) } & \multicolumn{2}{c}{ Glucose (mg\%) } \\
& $<50$ & $>50$ & $3-5$ & $>5$ & $<60$ & $>60$ \\
\hline 72 & 2 & 70 & 14 & 58 & 43 & 29 \\
\hline
\end{tabular}

Table 4: Role of cytology to establish definite diagnosis.

\begin{tabular}{llllc}
\hline $\begin{array}{l}\text { Initial } \\
\text { Clinical } \\
\text { Diagnosis }\end{array}$ & $\begin{array}{l}\text { No. of } \\
\text { samples }\end{array}$ & Cytological diagnosis & $\begin{array}{l}\text { No. of } \\
\text { samples }\end{array}$ & Percentage \\
\hline Tuberculosis & 80 & Tuberculosis & 72 & 90 \\
& & Metastatic adenocarcinoma & 5 & - \\
& & Mesothelioma & 1 & - \\
& & Metastatic papillary carcinoma & 1 & - \\
& & Metastatic small cell carcinoma & 1 & 80 \\
Malignancy & 50 & Malignant effusions & 40 & - \\
Pneumonia & 8 & Paramalignant & 10 & 100 \\
Undiagnosed & 1 & Pneumonia & 8 & - \\
\hline
\end{tabular}


G.G. Swamy et al, Role of pleural fluid analysis in establishing........

Clinically, 80 cases were diagnosed to be tuberculous in origin but tuberculosis was cytologically confirmed in 72 cases. Among the remaining eight cases of clinically suspected tuberculous effusion, five were of metastatic adenocarcinoma, one each of mesothelioma, metastatic papillary carcinoma and metastatic small

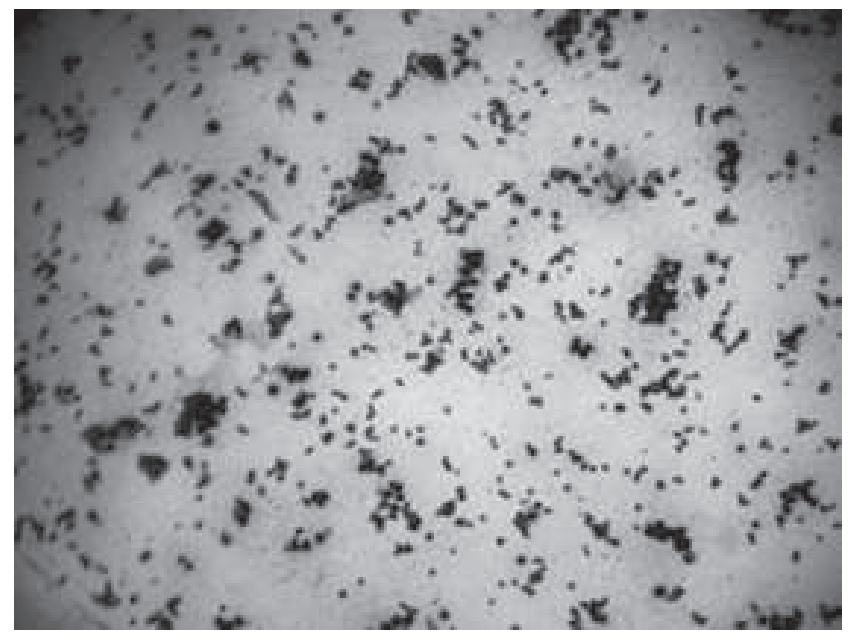

Fig-1, Tubeculous pleural effusion showing predominently

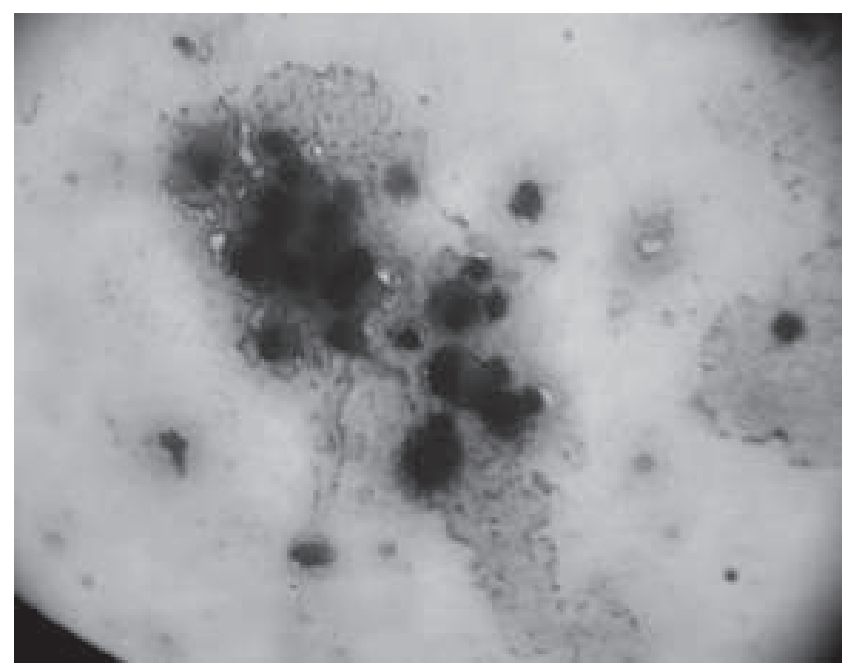

Fig-3, Mesothelioma cell carcinoma. Out of fifty clinically suspected malignant effusions, forty were diagnosed to be malignant after cytological examination. The remaining ten samples turned out to be paramalignant. All the samples of clinically diagnosed pneumonia correlated with cytological diagnosis. (Table. 4)

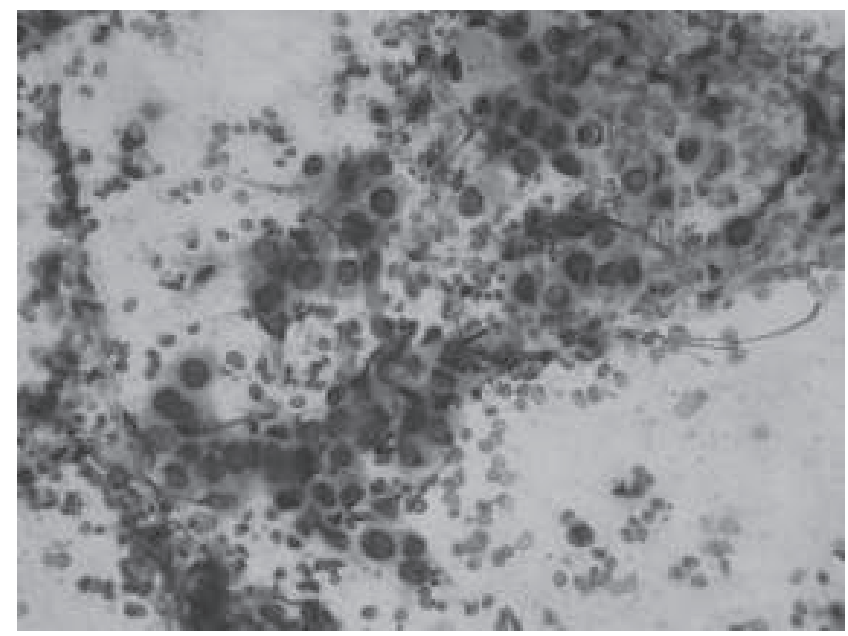

Fig-2, Metastatic adenocarcinoma 


\section{Discussion}

Pleural effusion is a frequently encountered problem in patients suffering from pulmonary or cardiac problems. Pleural effusion may be a transudate, if the cause is due to increased hydrostatic or decreased oncotic pressure in the pleural cavity; may be exudates, if there is abnormal pleural capillary permeability, reduced lymphatic clearance of accumulating fluid, infection or bleeding, into the pleural space. ${ }^{3}$ Hence, discrimination of the pleural fluid as transudate or exudate remains the basic diagnostic algorithm. For exudates, malignancy, bacterial pleurisy and tuberculous effusions are the principal differential diagnoses. $^{3}$

More often than not, a tuberculous pleural effusion is impossible to differentiate from a malignant pleural effusion on clinical grounds alone. ${ }^{8}$ Diagnostic methods traditionally used to diagnose tuberculosis and malignancy are either not absolutely precise or more invasive than they should be. ${ }^{8}$

Medical thoracoscopy, in trained hands of a pulmonologist is a safe and effective procedure for the diagnosis and therapy of various pleural diseases, but it is an invasive and expensive procedure, with a risk of complications like pneumothorax. ${ }^{9}$ Moreover, it is available at very select centers, and its cost is beyond the reach of an average person, in developing countries like Nepal. Moreover, a recent survey revealed that even in USA, only $6 \%$ of pulmonologists are currently trained in and perform this valuable procedure. ${ }^{9}$ By contrast, thoracentesis has been a very popular diagnostic as well as therapeutic procedure for tapping pleural effusions and has very few procedural complications.

In our study, pleural fluid analysis had given sufficient information to categorize the samples as transudates or exudates on the basis of biochemical tests and cell count. ${ }^{3}$ Moreover, we could provisionally categorize the samples as malignant, tuberculous, etc. by the cytological findings. ${ }^{3}$

The relative ease of pleural fluid aspiration, analysis and cytological examination has kept alive the search for a test to unequivocally differentiate the various causes of effusion. The cytological examination of body effusion is a complete diagnostic modality which aims at pointing out the etiology of effusions. The diagnostic performance of the cytological study of the fluid may be attributable to the fact that the cell population present is representative of a much larger surface area than that obtained by needle biopsy. ${ }^{6,7}$ The present study deals with the accuracy of diagnosis on the basis of contemporary cytological features and cell count. A total of 200 samples of pleural fluid were studied.

The clinical presentation of malignant tumor is an indispensable, effective aid to a cytopathologist and may increase the yield by several times. ${ }^{7}$ So, an attempt was made to study the relationship between clinical and cytological diagnosis.

The present study showed slight male preponderance with female to male ratio of 1:1.67. Our study is in concordance with the study of Romero et al. ${ }^{8}$ In our study, most of the effusions $(80 \%)$ were exudative in nature. Transudates comprised $20 \%$ of cases. Most of malignant 
effusions were exudative except ten cases which were transudates which could be explained on the basis of concomitant anemia and hypoproteinemia. In a study of Sherwani et al., ${ }^{7}$ two cases of malignancy had transudates due to similar reason.

The most frequent cause of exudative effusion was tuberculosis (45\%) followed by malignancy (30\%), paramalignant effusion (10\%), pneumonia (5\%) and empyema (5\%). The remaining cases were due to trauma, liver disease, hepatic abscess, pelvic abscess, myocardial infarction, and pancreatitis. Hence our study is in accordance with the study by Alusi. ${ }^{4}$

Transudative effusions are usually characterized by a majority of lymphocytes or other mononuclear cells. In our study also $80 \%$ samples of transudative effusion had more than 50\% lymphocytes. When exudative effusions are considered, all the tuberculous effusions had more than 50\% small lymphocytes. This pattern of lymphocyte predominance was observed in malignant and paramalignant effusions. Thus, our study correlates with the study of Light and Erozan. ${ }^{10}$ The pattern of predominantly polymorphonuclear cells was seen in most effusions secondary to pneumonia, post myocardial infarction, empyema, hepatic abscess, and pelvic abscess.

Our study is in accordance with the study done by Epstein et al. ${ }^{11}$ and showed that the majority of tuberculous effusions had more than $60 \%$ lymphocytes, $80 \%$ had proteins greater than $5 \mathrm{gm} /$ dl.

The presence of predominantly polymorphonuclear cells in pleural fluid indicates that the fluid is the result of acute pleural inflammation, hence raising the probability of pneumonia with effusion. In the present study, we had two traumatic cases where $15 \%$ eosinophils were found in the pleural fluid. So a diagnosis of eosinophilic pleural effusion was made. Fluid was hemorrhagic in nature. This can be attributed to the fact that the blood in the pleural space acts as an eosinotactic substance. Undoubtedly, there are other factors involved since a significant number of eosinophilic effusions are non-hemorrhagic and not all hemorrhagic effusions are eosinophilic. ${ }^{12}$ Air in pleural space has been shown to be another cause of eosinophilic inflammatory response.

It is possible to diagnose the type and source of malignant tumor cells in serous effusions with an overall accuracy of 50\%. In the present study, out of 48 samples with malignancy, the primary site could be confirmed on cytology in 30 cases. In our study the most common primary site was the pleura followed by the breast, ovary and lymphoma / leukaemia.

In the present study, pleural fluid cytology was not helpful in ascertaining the cause of pleural effusion in eighteen patients, thereby indicating its limitations.

Malignant pleural effusion was found to affect females more than males (2.3:1), which is similar to the study conducted by Sears et al. ${ }^{13}$

A single variable which strongly predicts malignancy is "bloody fluid". In our study, $70 \%$ of hemorrhagic effusions were positive for malignancy. But all hemorrhagic fluids need not be due to malignancy and non-hemorrhagic fluids 
can have malignant cells, which correlated with Rashmi Kushwaha et al. ${ }^{14}$

In the present study, mesothelioma was the second most common malignancy accounting for eleven samples. Mesothelial cells were arranged singly or in three dimensional groups. These cell clusters had spherical morule like configuration. Single atypical mesothelial cells were also present. Atypical nuclear features, such as variation in nuclear size, shape, multinucleation, hyperchromasia and enlarged nucleoli were seen. The cells had dense perinuclear cytoplasm, centrally placed nuclei and slit like spaces between some cells. There was also focal vacuolization of the cytoplasm and a prominent lymphocytic infiltrate. Grandos et al., ${ }^{15}$ showed similar findings in cytologic analysis of fluid from malignant mesothelioma.

Gaur et $\mathrm{al}^{16}$ found that Pleural fluid analysis with closed needle pleural biopsy can further enhance its usefulness in diagnosing pleural malignant lesions.

\section{Conclusion}

The present study demonstrated that the most useful test in establishing the diagnosis of pleural effusion is pleural fluid cytology and pleural fluid cell count. Cytological study of pleural fluid is a complete diagnostic modality which aims at pointing out the etiology of effusion as well as, in certain cases, a means of prognostication of disease process. The diagnostic performance may be attributable to the fact that the cell population present in the sediment is representative of a much larger surface area than that obtained by needle biopsy. Detailed study of cytomorphologic features of various metastatic malignant cells in pleural effusions provides definite clues regarding the primary site.

Thus, in developing countries like ours, where investigations and health facilities are inadequate and cost of treatment is often unaffordable, pleural fluid analysis and cytology should continue to be the first line investigation to screen out the suspiciously malignant pleural effusion cases, as it is very convenient, cost effective and safe investigation. It shows good sensitivity, specificity and accuracy in establishing the cause of pleural effusion.

\section{Acknowledgement}

We wish to thank Dr.J.M.Ahuja, Professor of Pathology for his encouragement and support.

We also thank the Biochemistry department for their cooperation and all clinical Departments for sending pleural fluid samples to our Department for examination and also special thank to Dr. Arjun Singh Lecturer, Dr.Sushna, Dr.Merina Rajbhandari, Dr.Rajina Sahi, Dr. Agya Shrestha Residents of Pathology, Dr. Binnam (Intern), Mr. P.K. Mishra, Mr. Prakash Lab technicians at Department of Pathology for their technical help. Our special thanks to Mrs. Shobha Neupane for her help in preparation of this manuscript. 


\section{References}

1. J. Kalomenidis. New advances in the investigation of pleural diseases. Pneumologie 2003; 16:247-51

2. B.D. Cheson. Clinical utility of body fluid analysis. Clin Lab Med 1985; 5:195-208.

3. M.S. Chesnutt, T.J Prendergast. Lung. In: Triney Jr LM, SJ McPhee, MA Papadakis, editors. Current medical diagnosis and treatment. $43^{\text {rd }}$ ed. USA:McGraw-Hill; 2004.212-305

4. F.A. Alusi. Pleural effusion in Iraq: A prospective study of 100 cases. Thorax 1986; 41:492-3.

5. A.N. Aggrawal, D. Gupta, S.K. Jindal. Diagnosis of tuberculous pleural effusion. Indian J Chest Dis Allied Sci 1999; 41:89-100.

6. B.First, A.V. Kahan, L.G. Koss. Comparison of the diagnostic values of biopsies of the pleura and cytologic evaluation of pleural fluids. Am J Clin Pathol 1979; 72:48-51.

7. R.Sherwani, K.Akhtar, A.H.Naqvi, et al. Diagnostic and prognostic significance of cytology in effusions. J Cytol 2005; 22:73-7.
8. S.Romero, A.Candela,C.Martin, et al. Evaluation of different criteria for the separation of pleural transudates from exudates. Chest 1993; 104:399-404.

9. P.N.Mathur, R.Loddenkemper. Biopsy techniques in the diagnosis of pleural diseases. European Respiratory Monograph 2002; 7:120-30.

10. R.W.Light, Y.S.Erozan,W.C.Ball. Cells in pleural fluid. Arch Intern Med 1973; 132:854-60.

11. D.M.Epstein,L.R.Kline, S.M. Albelda, et al. Tuberculous pleural effusions. Chest 1987; 91:106-9.

12. U.N. Kumar,B.Varkey,G. Mathai. Post traumatic pleural fluid and blood eosinophilia. JAMA 1975; 234:625-6.

13. D.Sears, S.I.Hajdu. The cytologic diagnosis of malignant neoplasms in pleural and peritoneal effusions. Acta Cytol 1987; 31:85-97.

14. K.Rashmi, P.Shashikala, S.Hiremath, et al. Cells in pleural fluid and their value in differential diagnosis. J Cytol 2008; 25(4):138-43.

15. R.Granados, E.S. Libas, J.A. Fletcher. Cytolgenetic analysis of effusions from malignant mesothelioma. Acta Cytol 1994; 38:711-7.

16. D.S.Gaur, N.Chauhan, A. Kusum, et al. Pleural fluid Analysis - Role in Diagnosing Pleural Malignancy. $J$ Cytol 2007; 24(4):183-8. 